\title{
VOLATILE COMPOUNDS IN GOLDEN DELICIOUS APPLE FRUIT (Malus domestica) DURING COLD STORAGE
}

\section{COMPUESTOS VOLÁTILES DE MANZANA (Malus domestica) GOLDEN DELICIOUS DURANTE ALMACENAMIENTO}

\author{
N. A. Salas ${ }^{1}$, G. A. González-Aguilar ${ }^{3}$, J. L. Jacobo-Cuéllar ${ }^{4}$, M. Espino², \\ D. Sepúlveda ${ }^{2}$, V. Guerrero ${ }^{1}$ and G. I. Olivas ${ }^{2 *}$
}

\begin{abstract}
'Facultad de Ciencias Agrotecnológicas, Universidad Autónoma de Chihuahua. Cuauhtémoc, Chih., México. "2Laboratorio de Tecnología de Alimentos de Origen Vegetal, Centro de Investigación en Alimentación y Desarrollo. Cuauhtémoc, Chih., México. ${ }^{3}$ Centro de Investigación en Alimentación y Desarrollo, A.C., Km 0.6 Carretera la Victoria. Hermosillo, Son., México. ${ }^{4}$ Campo Experimental Sierra de Chihuahua, INIFAP. Av. Hidalgo No. $1213, C u-$ auhtémoc, Chih. México.
\end{abstract}

*Corresponding autor: golivas@ciad.mx

\section{SUMMARY}

Biosynthesis of volatile compounds (VC), as well as activity of related enzymes (lipoxygenase LOX, alcohol acyltransferase AAT, and alcohol dehydrogenase $A D H$ ), and fatty acids (palmitic, stearic, oleic, linoleic and linolenic acids) were assessed in Golden Delicious fruit apples (Malus domestica Borkh.) during $1{ }^{\circ} \mathrm{C}$ storage at different atmosphere conditions. Three atmosphere conditions were used: $21 \% \mathrm{O}_{2}$ and > $1 \% \mathrm{CO}_{2}$ (Regular Atmosphere, RA), 3 $\% \mathrm{CO}_{2}$ and $2 \% \mathrm{O}_{2}$ (Controlled Atmosphere, $\mathrm{CA}$ ), and $\mathrm{CA}$, with $7 \mathrm{~d}$ under RA conditions $(C A+R A)$, to evaluate the effect of shorts periods under air storage. CA conditions inhibited the production of butyl acetate and hexyl acetate esters, and increased hexanol concentration. Production of the branched ester 2-methyl butyl acetate did not decrease under CA conditions. As a result of 7 $\mathrm{d}$ under RA, butyl acetate and hexyl acetate in CA + RA increased, mainly after one month of storage. Storage under CA conditions inhibited LOX and AAT activity at some stages whereas ADH activity increased during CA storage. LOX activity showed high correlation with production of aldehydes $\left(r^{2}=0.85\right)$ and cis-2-hexenal $\left(r^{2}=0.94\right)$, during storage of apples under CA conditions. Good correlation was found between AAT activity and total esters and butyl acetate content under CA storage of apples $\left(r^{2}=0.92\right.$ and $r^{2}=0.93$, respectively). While most fatty acids increased in concentration during RA and CA storage, linolenic acid content decreased. No correlation between volatile compounds content and fatty acid production was found.

Index words: Controlled atmosphere, enzymes, fatty acids, Malus domestica

\section{RESUMEN}

La biosíntesis de compuestos volátiles, así como la actividad de las enzimas involucradas (lipooxigenasa LOX, alcohol aciltransferasa AAT y alcohol deshidrogenasa ADH), y los ácidos grasos (palmítico, esteárico, oléico, linoléico y linolénico) fueron evaluados en manzana (Malus domestica Borkh.) var. Golden Delicious durante almacenamiento en refrigeración $\left(1^{\circ} \mathrm{C}\right)$ con diferentes condiciones de atmósfera: $21 \% \mathrm{O}_{2} \mathrm{y}>1 \% \mathrm{CO}_{2}$ (Atmósfera Regular, RA), $3 \% \mathrm{CO}_{2}$ y $2 \% \mathrm{O}_{2}$ (Atmósfera Controlada, $\mathrm{CA}$ ), y atmósfera controlada más $7 \mathrm{~d}$ en refrigeración bajo atmosfera regular, para evaluar el efecto de un corto periodo de almacenamiento en aire. La condición de CA inhibió la producción de ésteres como acetato de butilo y acetato de hexilo e incrementó la concentración de hexanol. El ester ramificado acetato de 2-metil butilo no fue afectado negativamente en condiciones de CA. Como resultado de $7 \mathrm{~d}$ en RA, en CA + RA el acetato de butilo y el acetato de hexilo se incrementaron, principalmente después del primer mes de almacenamiento. La actividad enzimática de LOX y AAT fueron inhibidas en algunas etapas durante el alma- cenamiento con CA. La actividad enzimática de la ADH incrementó durante el almacenamiento con CA. La actividad enzimática mostró correlación con el total de aldehídos $\left(r^{2}=0.85\right)$ y con la producción de cis 2-hexenal $\left(r^{2}=0.94\right)$, durante el almacenamiento en condiciones de CA. También se encontró correlación entre la actividad enzimática de AAT con el total de ésteres y acetato de butilo en condiciones de $\mathrm{CA}\left(\mathrm{r}^{2}=0.92 \mathrm{y} \mathrm{r}^{2}=0.93\right.$, respectivamente). En tanto, la mayoría de los ácidos grasos incrementaron su concentración durante el almacenamiento en RA y CA, el ácido linolénico disminuyó. No se encontró correlación entre los compuestos volátiles y la producción de ácidos grasos.

Palabras clave: Atmósfera controlada, enzimas, ácidos grasos, Malus domestica.

\section{INTRODUCTION}

Golden Delicious is the most cultivated apple (Malus domestica Borkh.) variety in Chihuahua, México (SAGARPA 2010). Flavor is the main quality attribute of apples from Chihuahua (Bismark, 2002; Olivas et al., 2007). Volatile compounds are essential and confer a complex combination of taste and odor (Defilippi et al., 2009).

More than 300 different volatile compounds have been identified in apples to date (Dixon and Hewett, 2000). The main precursors of volatile compounds in apple are fatty acids which are catabolized through $\beta$-oxidation and lipoxygenase (LOX) pathway (Pérez and Sanz, 2008), that produce straight chain aldehydes, alcohols, and esters. Aldehydes are predominant in immature apples (De Pooter et al., 1987), whereas alcohols and esters prevail in ripe fruits (Flath et al., 1967). Alcohol biosynthesis involves enzymes such as alcohol dehydrogenase (ADH; EC 1.1.1.1) and lipoxygenase (LOX; EC 1.13.11.12) (Defilippi et al., 2005; Echeverría et al., 2004a). Availability of alcohols is a limiting factor for ester biosynthesis (Berger and Drawert, 1984; Defilippi et al., 2005), since they are derived from a reaction catalyzed by alcohol acyltransferase (AAT; EC 2.3.1.84) involving esterification of alcohols and acyl-CoA (Sanz et al., 1997). Esters are qualitatively and quantitatively predominant in most 
apples, accounting for $80 \%$ of the total volatile content in Golden Delicious apples (López et al., 1998).

A small percentage of the fruit is commercialized immediately after harvest, while most of it is stored. Apples stored for a long periods of time are usually kept under controlled atmosphere (CA) conditions (Brackmann et al., 1994). Composition of the atmosphere under CA (1.5 - 1.7 $\% \mathrm{O}_{2}, 2-2.2 \% \mathrm{CO}_{2}$ ) differs from cold storage under regular atmosphere (RA) conditions $\left(78.08 \% \mathrm{~N}_{2}, 20.95 \% \mathrm{O}_{2}, 0.03 \%\right.$ $\mathrm{CO}_{2}$ ) (Kader, 2002). Recent research has shown that apple storage under CA may suppress production volatile compounds that create the typical aroma (Fellman et al., 2003; Lara et al., 2007; Singh et al., 2010; Starr et al., 2010; Lumpkin et al., 2015).

Fellman et al. (2000) found that Gala apples stored for long periods under a $1 \% \mathrm{O}_{2}$ and $1 \% \mathrm{CO}_{2}$ atmosphere suppressed flavor production. Echeverría et al. (2004b) found that $\mathrm{CA}\left(3 \% \mathrm{O}_{2}\right.$ and $\left.2 \% \mathrm{CO}_{2}\right)$ significantly suppressed volatile production after 5 months of storage, compared to apples cold-stored under RA. However, López et al. (2000) found that volatile compound emission in Golden Delicious apples increased after storage for 5 months under a low oxygen atmosphere; sampled apples kept acceptable levels of firmness, acidity, total soluble solids content, color, and high concentrations of branched-chain esters that intensified fruit flavor.

Since flavor depends on volatile biosynthesis, and Golden Delicious apples from Chihuahua, México are primarily recognized by their flavor, this study focused on volatile biosynthesis of fruit stored under CA, RA, and CA after 7 d under RA. Other variables like fatty acids quantification and measurement of activity of the enzymes lipoxygenase (LOX), alcohol acyltransferase (AAT), and alcohol dehydrogenase $(A D H)$ were also determined.

\section{MATERIALS AND METHODS}

\section{Plant material and storage conditions}

Thirty-five-year old Golden Delicious apple trees from a commercial orchard located in Cuauhtémoc, Chihuahua, México (28 23' 51.43" N, $106^{\circ} 49^{\prime} 05.79^{\prime \prime}$ W, at 2062 masl) were selected for this study. Apples were harvested 176 days after full bloom, when internal ethylene content (IEC) was $0.9 \mathrm{ppm}$. Ethylene production was used as a harvest index, according to Dhall (2013). Apples were selected according to color and weight to ensure uniformity in maturity and size, as well as consistent skin-pulp ratio in the analyzed samples. Apples were stored under CA (2 $\% \mathrm{O}_{2}$ and $\left.3 \% \mathrm{CO}_{2}\right), \mathrm{RA}\left(78.08 \% \mathrm{~N}_{2}, 20.95 \% \mathrm{O}_{2}, 0.03 \% \mathrm{CO}_{2}\right)$ (Kader, 2002), and CA followed by seven days at RA (CA +
RA) at $1{ }^{\circ} \mathrm{C}$. Volatile compound content, specific activity for the enzymes lipoxygenase (LOX), alcohol dehydrogenase $(\mathrm{ADH})$, and alcohol acyltransferase (AAT), and fatty acid composition were evaluated at harvest and after 1, 3, 5, and 7 months of storage.

\section{Aroma volatiles}

Volatiles concentration in apples was determined by gas chromatography-mass spectrometry (GC-MS) using the solid phase microextraction (SPME) technique, as described by Maya-Meraz et al. (2014). Apple juice from eight apples per treatment was obtained with a food processor (Turmix, México). The juice $(20 \mathrm{~mL}$ ) was placed in a $20 \mathrm{~mL}$ PTFE (polytetrafluoroethylene) vial, frozen in liquid nitrogen, and kept at $-70^{\circ} \mathrm{C}$ until analysis. An aliquot of $2 \mathrm{~mL}$ of thawed apple juice was placed in a $4 \mathrm{~mL}$ vial containing 0.7 $\mathrm{g}$ of sodium chloride, and stirred while a SPME fiber $(65 \mu \mathrm{m}$, PDMS-DVB, Supelco, USA) was exposed to the headspace of the sample for $1 \mathrm{~h}$ at room temperature $\left(25^{\circ} \mathrm{C}\right)$. The fiber was desorbed by splitless injection for $5 \mathrm{~min}$ at $200^{\circ} \mathrm{C}$ into a GC-MS system (Varian Saturn 2100D GC/MS; California, USA) equipped with an Equity-1 column ( $60 \mathrm{~m} \times 0.25 \mathrm{~mm}$ ID $\times 0.25 \mu \mathrm{m}$ film thickness; Supelco, USA).

Chromatographic conditions were, initial oven temperature of $33^{\circ} \mathrm{C}$ held for $5 \mathrm{~min}$, increased to $50^{\circ} \mathrm{C}$ at $2^{\circ} \mathrm{C} \mathrm{min}-1$, then increased to $250^{\circ} \mathrm{C}$ at $5^{\circ} \mathrm{C} \mathrm{min}-1$, and held for $6.5 \mathrm{~min}$. Helium was used as carrier gas with a flow rate of $1 \mathrm{~mL}$ $\mathrm{min}^{-1}$. Mass spectra were obtained by electron impact ionization at $70 \mathrm{eV}$. Transfer line and ion source temperatures were 250 and $180^{\circ} \mathrm{C}$, respectively. Spectra were recorded with a Saturn GC/MS workstation (Varian).

Volatile organic compounds (VOCs) of interest were identified by spectral match to the National Institute of Standards and Technology (1998), Mass Spectral Library (NIST 98 MS) and by comparison of retention times against high purity standards (ethanol, 2-propanol, 2-methyl1-propanol, 1-butanol, 2-methyl-1-butanol, 1-pentanol, 3-hexen-1-ol (Z), 2-hexen-1-ol (E), 1-hexanol, 1-heptanol, 1-octanol, 2-ethyl 1-hexanol, acetaldehyde, butanal, 2-methyl butanal, pentanal, hexanal, 2-hexenal, benzaldehyde, octanal, nonanal, decanal, ethyl acetate, 1-methyl ethyl acetate, propyl acetate, 2-methyl propyl acetate, butyl acetate, 2-methyl butyl acetate, pentyl acetate, 2-buten-1-ol, 3-methyl acetate, 3-hexen-1-ol acetate, hexyl acetate, ethyl propanoate, propyl propanoate, butyl propanoate, hexyl propanoate, methyl butanoate, methyl-2methyl butanoate, ethyl butanoate, ethyl-2-methyl butanoate, butyl butanoate, butyl 2-methyl butanoate, hexyl butanoate, hexyl 2-methyl butanoate, ethyl pentanoate, ethyl hexanoate, propyl hexanoate, hexyl hexanoate, and ethyl octanoate) (Sigma-Aldrich and ChemService). 
Quantification was accomplished by external standard calibration curves using peak areas. All values represent the average of triplicated samples consisting of eight apples each. Acidity and soluble solids contents were measured in the same juice.

\section{Lipoxygenase specific activity}

Peel and cortical tissue from eight apple fruits per treatment were freeze-dried with a Labconco, Freezone 12 (Labconco, Corporation, USA). A $200 \mathrm{mg}$ aliquot of the freeze-dried tissues mentioned above was homogenized three times for $20 \mathrm{~s}$ with $5 \mathrm{~mL}$ of an extraction solution (0.5 M sodium phosphate buffer $\mathrm{pH} 6.5,4 \mathrm{mM}$ dithiothreitol, 1 mM EDTA, $0.2 \%$ Triton $\mathrm{X}-100$, and $1 \%$ polyvinylpolypyrrolidone) using an UltraTurrax T25 homogenizer (IKA Labortechnik, Staufen, Germany). The slurry obtained was filtered through two cheesecloth layers and centrifuged at $25,000 \times \mathrm{g}$ for $15 \mathrm{~min}$. The pellet was discarded, and the supernatant was used as crude extract.

LOX activity was assayed spectrophotometrically at 234 $\mathrm{nm}$ and $30^{\circ} \mathrm{C}$ by monitoring the formation of conjugated dienes from linoleic acid, according to Wang et al. (2004). The assayed mixture $(3 \mathrm{~mL})$ consisted of $2.75 \mathrm{~mL}$ sodium phosphate buffer (100 mM, pH 6.5), $50 \mu \mathrm{L}$ sodium linoleic acid solution $(10 \mathrm{mM})$, and $0.2 \mathrm{~mL}$ crude extract. Each determination was done in triplicate, and one activity unit $(U)$ was defined as the increment in one unit of absorbance per minute. Results were expressed as specific activity $\left(\mathrm{U} \mathrm{mg}^{-1}\right.$ of protein) (Wang et al., 2004).

\section{Alcohol acyltransferase specific activity (AAT)}

AAT activity was assayed according to the modified Pérez et al. (1996) method. A $10 \mathrm{mg}$ sample of freezedried apple (containing peel and cortical tissue) was homogenized in $1 \mathrm{~mL}$ of extraction solution ( $0.1 \mathrm{M}$ sodium phosphate buffer $\mathrm{pH}$ 8.0, 1 mM EDTA, $0.1 \%$ Triton X-100, and $1 \%$ PVPP) utilizing an UltraTurrax T25 homogenizer. The homogenate was centrifuged at 20,800 $\mathrm{xg}$ for $20 \mathrm{~min}$ at $4{ }^{\circ} \mathrm{C}$. The supernatant was recovered and set on ice as crude enzyme extract. AAT activity was assayed by mixing $2.5 \mathrm{~mL} \mathrm{MgCl}$, solution ( $5 \mathrm{mM} \mathrm{MgCl}$ in $0.1 \mathrm{M}$ sodium phosphate buffer $\mathrm{pH}$ 8.0), $150 \mu \mathrm{L}$ of acetyl-CoA solution (2.5 mM acetyl-CoA in $0.1 \mathrm{M}$ sodium phosphate buffer $\mathrm{pH}$ 8.0), $50 \mu \mathrm{L}$ butanol solution ( $200 \mathrm{mM}$ butanol in $0.1 \mathrm{M}$ sodium phosphate buffer $\mathrm{pH} 8.0$ ), and $200 \mu \mathrm{L}$ crude extract. The mixture was incubated at $35^{\circ} \mathrm{C}$ for $15 \mathrm{~min}$. After that $100 \mu \mathrm{L}$ of $10 \mathrm{mM}$ 5,5-dithiobis (nitrobenzoic acid) (DTNB) were added, and the mixture allowed to stand at room temperature for $10 \mathrm{~min}$.

AAT activity was measured spectrophotometrically by the increment in absorbance at $412 \mathrm{~nm}$ as a yellow thiophenol complex of DTNB and free Coenzyme A(CoA) liberated during the catalytic reaction formed. Each determination was carried out in triplicate: one activity unit $(U)$ was defined as the increment in one absorbance unit at $412 \mathrm{~nm}$ per minute. Results were expressed as AAT specific activity (mUmg-1 of protein) (Echeverría et al., 2004a).

\section{Alcohol dehydrogenase specific activity (ADH)}

The method used for extraction of $\mathrm{ADH}$ was described by Chang et al. (1982). A 100 mg freeze-dried apple (containing peel and cortical tissue) sample was homogenized three times for $20 \mathrm{~s}$ with $5 \mathrm{~mL}$ extraction solution $(10 \mathrm{mM}$ sodium phosphate buffer $\mathrm{pH}$ 8.0, $5 \mathrm{mM}$ dithiothreitol and $0.5 \%$ polyvinylpolypyrrolidone). The homogenate was centrifuged at $15,000 \times \mathrm{g}$ for $15 \mathrm{~min}$ at $4{ }^{\circ} \mathrm{C}$. The pellet was discarded, and the supernatant was used as crude extract. The reduction of acetaldehyde was followed spectrophotometrically at $25^{\circ} \mathrm{C}$ by measuring the change in absorbance at $340 \mathrm{~nm}$ for $2 \mathrm{~min}$ of a reaction mixture containing 800 $\mathrm{mL}$ of a $25 \mathrm{mM}$ MES (2-(N-morpholino) ethanesulfonic acid) buffer at $\mathrm{pH} 7.2,50 \mathrm{~mL}$ of nicotinamide adenine dinucleotide (NADH) (5 mM), $100 \mathrm{~mL}$ of enzyme extract, and $50 \mathrm{~mL}$ of acetaldehyde $(80 \mathrm{mM})$. Each determination was done in triplicate; one activity unit $(U)$ was defined as the decrease in one unit of absorbance at $340 \mathrm{~nm}$ per minute, and results were expressed as specific activity $\left(U \mathrm{mg}^{-1}\right.$ protein).

\section{Fatty acid analysis}

Fatty acids content was determined by fatty acid methyl ester (FAME) analysis according to slight modifications to Defilippi et al. (2005). A $0.15 \mathrm{~g}$ sample of freeze-dried apple (containing peel and cortical tissue) was mixed with $1 \mathrm{~mL}$ of toluene and shaken overnight (100 rpm) at room temperature on an orbital shaker. Subsequently, $500 \mu \mathrm{L}$ of methanolic $0.5 \mathrm{~N}$ sodium methoxide was added and shaken for $1 \mathrm{~h}(100 \mathrm{rpm})$ at room temperature. After the hour, the transesterification reaction was terminated by addition of $50 \mu \mathrm{L}$ of a $10 \% \mathrm{NaCl}$ solution. Finally, $400 \mu \mathrm{L}$ of heptane was added, mixed and centrifuged for $5 \mathrm{~min}$ at $1400 \times \mathrm{g}$. After phase separation, an aliquot of the upper phase was transferred to a vial and refrigerated for further analysis.

Fatty acid composition was determined by gas chromatography using a 7820 Agilent instrument equipped with a flame-ionization detector. The instrument was fitted with a DB-Wax capillary column (30 m, $0.25 \mathrm{~mm}$ I. D. $0.25 \mu \mathrm{m})$. Injector port and detector temperatures were 250 and 300 ${ }^{\circ} \mathrm{C}$, respectively. Oven temperature was initially set at $50^{\circ} \mathrm{C}$, increased to $200{ }^{\circ} \mathrm{C}$ at a rate of $25^{\circ} \mathrm{C} \mathrm{min}-1$, increased to $230^{\circ} \mathrm{C}$ at a rate of $3^{\circ} \mathrm{C} \mathrm{min}^{-1}$ and held in that condition for 
$4 \mathrm{~min}$. The carrier gas was helium with a flow rate of $1 \mathrm{~mL}$ $\mathrm{min}^{-1}$. Identification of FAMEs was done by comparing the retention times to those of high purity standards analyzed under identical chromatographic conditions. Each determination was done in triplicate.

\section{Statistical analysis}

For statistical analysis, a mixed model design was used with storage conditions, storage period, and replication as fixed factors, and replications nested in treatments as random factors. Analyses were carried out using SAS Version 9 (SAS Institute, Cary, NC). Means were separated by (Least Squares) LS means test at $P \leq 0.05$. Volatile compounds data collected were analyzed by PROC MIXED for the analysis of a repeated measures factorial ANOVA and the statistical comparison of means was Tukey's range test method.

\section{RESULTS AND DISCUSSION}

\section{Volatile compounds}

In this study, 35 volatile compounds (VC) were identified and quantified during storage of Golden Delicious apples. The compounds identified included 18 esters: ethyl acetate, n-propyl acetate, 2-methyl propyl acetate, butyl acetate, 2-methyl butyl acetate, ethyl pentanoate, butyl propanoate, pentyl acetate, butyl butanoate, 3-hexen-1-ol acetate, hexyl acetate, butyl 2-methyl butanoate, propyl hexanoate, hexyl propanoate, hexyl butyrate, ethyl octanoate, hexyl 2-methyl butyrate, hexyl hexanoate; seven aldehydes: butanal, butanal 2-methyl, pentanal, cis 3-hexenal, hexanal, 2-hexenal, nonanal; and ten alcohols: 1-butanol, 2 methyl 1-propanol, 2 methyl 1-butanol, 1-pentanol, 3-hexen-1-ol (Z), 2-hexen-1-ol (E), 1-hexanol, 1-heptanol, 2-ethyl 1-hexanol, 1-octanol. Storage under CA caused a decrease on VC development (Figure 1). Mattheis et al. (1995), Fellman et al. (2003) and Saquet et al. (2003) found similar results for Bisbee Delicious, Redchief Delicious and Jonagold apples, respectively.

The main VC found in Golden Delicious apples at harvest time were (in decreasing order) 2-hexenal, 2-methyl 1-butanol, hexanal, butyl acetate, 2-methyl 1-propanol, 2-methyl butyl acetate, cis 3-hexenal, and hexyl acetate (Table 1). Significant interaction between different atmospheric conditions and storage time was detected. CA and CA + RA apples showed their highest total $\mathrm{VC}$ values after one month of storage, with no significant differences among CA, CA + $R A$, and RA $(P<0.05)$ (Figure 1). However, although total VC values were similar among treatments after one month of storage, their specific composition was different for each treatment (Figure 1, Table 1).
Treatment RA presented considerably higher concentration of esters (mainly butyl acetate) when compared to $\mathrm{CA}+\mathrm{RA}$ and CA apples, after one month of storage $(\mathrm{P}<$ 0.05). $C A+R A$ treatment induced $78 \%$ higher ester values than CA-treated apples, essentially butyl acetate, after one month of storage. On the other hand, CA-treated apples had $27.3 \%$ higher aldehyde concentration and $58 \%$ more alcohol levels than RA and CA + RA apples (mainly hexanol and 2-metyl-1-butanol) after one month of storage (Figure 1, Table 1).

Butyl acetate (66.7\%, 46.9 ppm), hexanal $(8.6 \%, 6.0$ ppm), and 2-hexenal (6.5\%, $4.5 \mathrm{ppm})$ make up about 82 $\%$ of the total VC produced by apples, after one month of RA storage. Compounds 2-hexenal (34.7\%, $17.7 \mathrm{ppm})$, 1-hexanol (30 \%, $15.3 \mathrm{ppm}$ ) and 2-methyl 1-butanol (14.5 $\%, 7.4 \mathrm{ppm}$ ) account for $80 \%$ of the total VC by CA stored apples after one-month storage. Butyl acetate (34.5\%, 13 ppm), 2-hexenal (27.9\%, 10.5 ppm), and 1-hexanol (13.5\%, $5 \mathrm{ppm}$ ) amount to about $76 \%$ of total VC by CA + RA stored apples, after month one of storage.

CA conditions inhibited the production of butyl acetate and hexyl acetate and increased hexanol concentration, after one month of storage. At this moment, branched ester, 2-methyl butyl acetate, increased on CA apples. According to López et al. (1998) branch chain esters are not affected by CA storage, since these come from the amino acid pathway. Fellman et al. (1993) found greater concentration of 2-methyl butyl acetate on apples stored under CA conditions, when compared to RA apples.

Seven days of RA after CA caused a regeneration of volatiles to get a composition resembling RA apples at month one of storage: ester biosynthesis was present, mainly butyl acetate, and concentration of alcohols and aldehydes (mainly 1-hexanol and 2-hexenal) decreased (Figure 1, Table 1). These results have important sensory implications: studies on commercial apple odor have correlated 'unwanted essences' with high levels of alcohols like hexanol which give an earthy unpleasant flavor, and 'desirable essences' with high levels of hexanal, 2-hexenal, and butyl acetate (Dürr and Schobinger, 1981; Petró-Turza et al., 1986). Altisent et al. (2011) found that the emission of 26 volatile compounds increased on Golden Reinders apples, after a regeneration period (air storage) of 2 and 4 weeks after ultralow-oxygen storage. According to Dixon and Hewett (2000), after hypoxia apples increase ester concentration. Young et al. (2004) indicated that low molecular weight esters increase more rapidly than their counterparts.

RA apples showed a four-fold value on total VC when compared to CA and CA + RA apples after three months of 


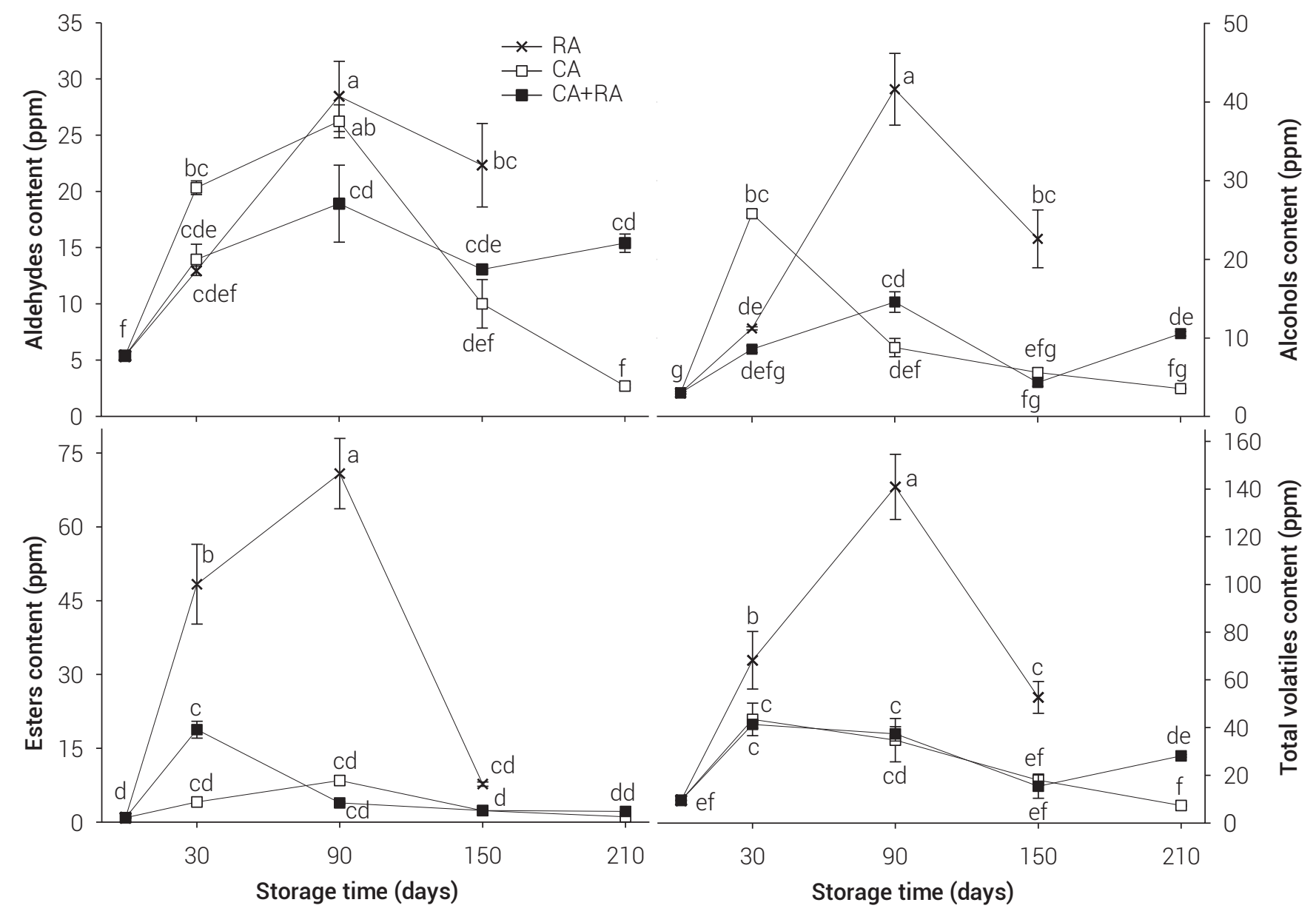

Figure 1. Aldehyde, alcohol, ester and total volatile content in Golden Delicious apple fruits under different storage conditions. Values represent mean of three repetitions. Vertical bars represent \pm SE. Means showing different letters are significantly different (Tukey, 0.05).

Table 1. Production of volatiles compounds (ppm) by Golden Delicious apples under different storage conditions.

\begin{tabular}{|c|c|c|c|c|c|}
\hline \multirow{2}{*}{ Aroma compound } & \multirow{2}{*}{ At harvest } & \multirow{2}{*}{ Months } & \multicolumn{3}{|c|}{ Storage condition } \\
\hline & & & RA & CA & $\mathrm{CA}+\mathrm{RA}$ \\
\hline \multicolumn{6}{|c|}{ Aldehydes } \\
\hline \multirow[t]{4}{*}{ Butanal } & Traces & 1 & $0.067 \mathrm{aA}$ & $0.045 \mathrm{aA}$ & $0.279 \mathrm{aB}$ \\
\hline & & 3 & $0.217 \mathrm{bA}$ & $0.410 \mathrm{bB}$ & $0.670 \mathrm{bc}$ \\
\hline & & 5 & $0.08 \mathrm{aA}$ & $0.0256 \mathrm{aA}$ & Traces \\
\hline & & 7 & - & Traces & Traces \\
\hline \multirow[t]{4}{*}{ Butanal 2-methyl } & ND & 1 & $0.002 \mathrm{a}$ & ND & ND \\
\hline & & 3 & $0.005 b$ & ND & ND \\
\hline & & 5 & $0.002 \mathrm{a}$ & ND & ND \\
\hline & & 7 & - & ND & ND \\
\hline \multirow[t]{4}{*}{ Pentanal } & Traces & 1 & $0.002 \mathrm{a}$ & Traces & Traces \\
\hline & & 3 & $0.002 a$ & Traces & Traces \\
\hline & & 5 & $0.001 \mathrm{a}$ & Traces & Traces \\
\hline & & 7 & - & Traces & Traces \\
\hline
\end{tabular}


Table 1. Continuity.

\begin{tabular}{|c|c|c|c|c|c|}
\hline \multirow{2}{*}{ Aroma compound } & \multirow{2}{*}{ At harvest } & \multirow{2}{*}{ Months } & \multicolumn{3}{|c|}{ Storage condition } \\
\hline & & & RA & CA & $\mathrm{CA}+\mathrm{RA}$ \\
\hline \multirow[t]{4}{*}{ cis 3-hexenal } & 0.154 & 1 & $0.096 \mathrm{aA}$ & $0.709 \mathrm{aB}$ & $0.371 \mathrm{aC}$ \\
\hline & & 3 & $0.098 \mathrm{aA}$ & $0.386 \mathrm{bB}$ & $0.398 \mathrm{aB}$ \\
\hline & & 5 & $0.149 \mathrm{aA}$ & $0.424 \mathrm{bB}$ & $0.206 \mathrm{bAC}$ \\
\hline & & 7 & - & $0.148 \mathrm{cA}$ & 0.104 bA \\
\hline \multirow[t]{4}{*}{ Hexanal } & 1.576 & 1 & $6.033 \mathrm{aA}$ & $2.546 \mathrm{aA}$ & $2.848 \mathrm{aA}$ \\
\hline & & 3 & $15.740 \mathrm{bA}$ & $4.990 \mathrm{aB}$ & $6.384 \mathrm{aB}$ \\
\hline & & 5 & $18.164 \mathrm{bA}$ & $5.492 \mathrm{aB}$ & $4.495 \mathrm{aB}$ \\
\hline & & 7 & - & $2.536 \mathrm{aA}$ & $3.098 \mathrm{aA}$ \\
\hline \multirow[t]{4}{*}{ 2-hexenal } & 3.640 & 1 & $4.571 \mathrm{aA}$ & $17.659 \mathrm{aB}$ & $10.452 \mathrm{abc}$ \\
\hline & & 3 & $12.427 \mathrm{bA}$ & $19.441 \mathrm{aB}$ & $11.452 \mathrm{abA}$ \\
\hline & & 5 & $3.922 \mathrm{aA}$ & $4.051 \mathrm{bA}$ & $7.320 \mathrm{aA}$ \\
\hline & & 7 & - & Traces & $12.185 b$ \\
\hline \multirow[t]{4}{*}{ Nonanal } & 0.0007 & 1 & $0.001 \mathrm{aA}$ & $0.002 \mathrm{aA}$ & $0.002 \mathrm{aA}$ \\
\hline & & 3 & $0.002 \mathrm{aA}$ & $0.002 \mathrm{aA}$ & $0.001 \mathrm{aA}$ \\
\hline & & 5 & $0.002 \mathrm{aA}$ & $0.002 \mathrm{aA}$ & $0.002 \mathrm{aA}$ \\
\hline & & 7 & - & $0.002 \mathrm{aA}$ & $0.002 \mathrm{aA}$ \\
\hline \multicolumn{6}{|c|}{ Alcohols } \\
\hline \multirow[t]{4}{*}{ 1-butanol } & 0.033 & 1 & 3.822 aA & $0.969 \mathrm{abB}$ & $1.250 \mathrm{aB}$ \\
\hline & & 3 & $7.541 \mathrm{bA}$ & $2.071 \mathrm{bB}$ & $1.910 \mathrm{aB}$ \\
\hline & & 5 & $1.560 \mathrm{cA}$ & $0.145 \mathrm{aB}$ & $0.003 \mathrm{aB}$ \\
\hline & & 7 & - & Traces & Traces \\
\hline \multirow[t]{4}{*}{ 2-methyl 1-propanol } & 0.448 & 1 & $0.455 \mathrm{aA}$ & $1.832 \mathrm{aB}$ & $0.721 \mathrm{aA}$ \\
\hline & & 3 & $0.674 \mathrm{aA}$ & $1.435 \mathrm{aB}$ & $0.685 \mathrm{aA}$ \\
\hline & & 5 & $0.542 \mathrm{aA}$ & $2.469 \mathrm{bB}$ & 1.274 bC \\
\hline & & 7 & - & $1.599 \mathrm{aA}$ & $2.673 \mathrm{cB}$ \\
\hline \multirow[t]{4}{*}{ 2-methyl 1-butanol } & 2.525 & 1 & $2.170 \mathrm{aA}$ & $7.371 \mathrm{aB}$ & $1.446 \mathrm{aA}$ \\
\hline & & 3 & $31.314 \mathrm{bA}$ & $0.849 \mathrm{bB}$ & $1.514 \mathrm{aB}$ \\
\hline & & 5 & $20.165 \mathrm{cA}$ & $0.676 \mathrm{bB}$ & $1.160 \mathrm{aB}$ \\
\hline & & 7 & - & $0.690 \mathrm{bA}$ & $2.541 \mathrm{aA}$ \\
\hline \multirow[t]{4}{*}{ 1-pentanol } & 0.012 & 1 & $0.011 \mathrm{aA}$ & $0.388 \mathrm{aB}$ & $0.141 \mathrm{aC}$ \\
\hline & & 3 & $0.014 \mathrm{aA}$ & $0.110 \mathrm{bB}$ & $0.107 \mathrm{aB}$ \\
\hline & & 5 & $0.003 \mathrm{aA}$ & $0.067 \mathrm{bcA}$ & $0.018 \mathrm{bA}$ \\
\hline & & 7 & - & $0.006 \mathrm{cA}$ & $0.010 \mathrm{bA}$ \\
\hline \multirow[t]{4}{*}{ 3-hexen-1-ol (Z) } & 0.003 & 1 & Traces & $0.004 \mathrm{aA}$ & $0.001 \mathrm{aB}$ \\
\hline & & 3 & Traces & $0.001 \mathrm{bA}$ & $0.001 \mathrm{aA}$ \\
\hline & & 5 & Traces & $0.002 \mathrm{bA}$ & $0.002 \mathrm{bA}$ \\
\hline & & 7 & Traces & $0.001 \mathrm{bA}$ & $0.002 \mathrm{bA}$ \\
\hline \multirow[t]{4}{*}{ 2-hexen-1-ol (E)- } & 0.005 & 1 & $0.005 \mathrm{aA}$ & 0.002 B & ND \\
\hline & & 3 & Traces & Traces & 1.909 \\
\hline & & 5 & $0.0006 b$ & Traces & Traces \\
\hline & & 7 & - & Traces & Traces \\
\hline
\end{tabular}


Table 1. Continuity.

\begin{tabular}{|c|c|c|c|c|c|}
\hline \multirow{2}{*}{ Aroma compound } & \multirow{2}{*}{ At harvest } & \multirow{2}{*}{ Months } & \multicolumn{3}{|c|}{ Storage condition } \\
\hline & & & RA & CA & $\mathrm{CA}+\mathrm{RA}$ \\
\hline \multirow[t]{4}{*}{ 1-hexanol } & 0.061 & 1 & $4.781 \mathrm{aA}$ & $15.246 \mathrm{aB}$ & $5.038 \mathrm{aA}$ \\
\hline & & 3 & $2.303 \mathrm{bA}$ & $4.330 \mathrm{bB}$ & $10.361 \mathrm{bc}$ \\
\hline & & 5 & $0.348 \mathrm{cA}$ & $2.280 \mathrm{cB}$ & $1.910 \mathrm{CAB}$ \\
\hline & & 7 & - & $1.280 \mathrm{cA}$ & $5.331 \mathrm{aB}$ \\
\hline \multirow[t]{4}{*}{ 1-heptanol } & 0.003 & 1 & 0.002 aA & $0.002 \mathrm{aA}$ & $0.003 \mathrm{aA}$ \\
\hline & & 3 & 0.004 bA & $0.002 \mathrm{aB}$ & $0.003 \mathrm{aA}$ \\
\hline & & 5 & $0.003 \mathrm{aA}$ & $0.002 \mathrm{aB}$ & $0.003 \mathrm{aA}$ \\
\hline & & 7 & - & $0.001 \mathrm{bA}$ & 0.002 bA \\
\hline \multirow[t]{4}{*}{ 2-ethyl 1-hexanol } & 0.0005 & 1 & $0.0006 \mathrm{a}$ & Traces & Traces \\
\hline & & 3 & 0.0009 b & Traces & Traces \\
\hline & & 5 & $0.001 \mathrm{bA}$ & Traces & $0.002 \mathrm{aB}$ \\
\hline & & 7 & - & Traces & $0.002 \mathrm{a}$ \\
\hline \multirow[t]{4}{*}{ 1-octanol } & 0.001 & 1 & $0.0006 \mathrm{aA}$ & Traces & $0.0009 \mathrm{aB}$ \\
\hline & & 3 & $0.0008 \mathrm{aA}$ & $0.0005 \mathrm{~A}$ & 0.004 bB \\
\hline & & 5 & $0.0008 \mathrm{aA}$ & Traces & $0.0007 \mathrm{aA}$ \\
\hline & & 7 & - & Traces & Traces \\
\hline \multicolumn{6}{|c|}{ Esters } \\
\hline \multirow[t]{4}{*}{ Ethyl acetate } & 0.002 & 1 & $0.006 \mathrm{aA}$ & $0.004 \mathrm{aA}$ & $0.024 \mathrm{aB}$ \\
\hline & & 3 & 0.014 bA & $0.005 \mathrm{aB}$ & 0.007 bB \\
\hline & & 5 & 0.012 bA & $0.002 \mathrm{aB}$ & 0.008 bC \\
\hline & & 7 & - & $0.002 \mathrm{aA}$ & 0.007 bB \\
\hline \multirow[t]{4}{*}{ n-Propyl acetate } & 0.002 & 1 & $0.002 \mathrm{aA}$ & $0.005 \mathrm{aA}$ & $0.002 \mathrm{aA}$ \\
\hline & & 3 & $0.125 \mathrm{bA}$ & $0.011 \mathrm{aB}$ & $0.002 \mathrm{aB}$ \\
\hline & & 5 & $0.151 \mathrm{~b}$ & Traces & Traces \\
\hline & & 7 & - & Traces & Traces \\
\hline 2-methyl propyl & 0.006 & 1 & $0.011 \mathrm{abA}$ & $0.025 \mathrm{aB}$ & $0.005 \mathrm{aC}$ \\
\hline \multirow[t]{3}{*}{ Acetate } & & 3 & 0.009 aA & 0.012 bA & $0.002 \mathrm{aB}$ \\
\hline & & 5 & 0.015 bA & $0.016 \mathrm{cbA}$ & $0.011 \mathrm{bA}$ \\
\hline & & 7 & - & $0.018 \mathrm{cA}$ & 0.029 cB \\
\hline \multirow[t]{4}{*}{ Butyl acetate } & 0.774 & 1 & 46.938 aA & $1.945 \mathrm{aB}$ & $12.945 \mathrm{aC}$ \\
\hline & & 3 & $68.420 \mathrm{bA}$ & $6.715 \mathrm{aB}$ & $2.797 \mathrm{bB}$ \\
\hline & & 5 & 5.908 cA & $1.388 \mathrm{aA}$ & 1.482 bA \\
\hline & & 7 & - & $0.895 \mathrm{aA}$ & 1.407 bA \\
\hline \multirow[t]{4}{*}{ 2-methyl butyl acetate } & 0.236 & 1 & $0.487 \mathrm{aA}$ & $1.617 \mathrm{aB}$ & $0.681 \mathrm{aA}$ \\
\hline & & 3 & $1.298 \mathrm{bA}$ & 1.078 bA & $0.134 \mathrm{bcB}$ \\
\hline & & 5 & $0.570 \mathrm{aAB}$ & $0.713 \mathrm{cA}$ & $0.354 \mathrm{bdB}$ \\
\hline & & 7 & - & $0.020 \mathrm{dA}$ & $0.528 \mathrm{adB}$ \\
\hline \multirow[t]{3}{*}{ Ethyl pentanoate } & Traces & 1 & $0.002 \mathrm{a}$ & Traces & Traces \\
\hline & & 3 & $0.004 \mathrm{~b}$ & Traces & Traces \\
\hline & & 5 & $0.002 \mathrm{a}$ & Traces & Traces \\
\hline
\end{tabular}


Table 1. Continuity.

\begin{tabular}{|c|c|c|c|c|c|}
\hline \multirow{2}{*}{ Aroma compound } & \multirow{2}{*}{ At harvest } & \multirow{2}{*}{ Months } & \multicolumn{3}{|c|}{ Storage condition } \\
\hline & & & RA & $\mathrm{CA}$ & $C A+R A$ \\
\hline & & 7 & - & Traces & Traces \\
\hline \multirow[t]{4}{*}{ Butyl propanoate } & 0.002 & 1 & $0.006 \mathrm{aA}$ & $0.004 \mathrm{aA}$ & $0.0019 \mathrm{aB}$ \\
\hline & & 3 & $0.018 \mathrm{bA}$ & $0.002 \mathrm{bB}$ & $0.0006 \mathrm{aB}$ \\
\hline & & 5 & $0.013 c$ & Traces & Traces \\
\hline & & 7 & - & Traces & Traces \\
\hline \multirow[t]{4}{*}{ Pentyl acetate } & 0.007 & 1 & $0.023 \mathrm{aA}$ & $0.051 \mathrm{aB}$ & $0.059 \mathrm{aA}$ \\
\hline & & 3 & $0.027 \mathrm{aA}$ & $0.040 \mathrm{aB}$ & $0.035 \mathrm{bAB}$ \\
\hline & & 5 & $0.029 \mathrm{aA}$ & $0.024 \mathrm{bA}$ & $0.026 \mathrm{bcB}$ \\
\hline & & 7 & - & $0.016 \mathrm{bA}$ & $0.020 \mathrm{cB}$ \\
\hline \multirow[t]{4}{*}{ Butyl butanoate } & 0.002 & 1 & $0.029 \mathrm{aA}$ & $0.009 \mathrm{aB}$ & $0.025 a b A$ \\
\hline & & 3 & $0.061 \mathrm{bA}$ & $0.015 \mathrm{aB}$ & $0.016 \mathrm{bcB}$ \\
\hline & & 5 & $0.035 \mathrm{aA}$ & $0.003 \mathrm{aB}$ & $0.007 \mathrm{cB}$ \\
\hline & & 7 & - & $0.003 \mathrm{aA}$ & $0.014 \mathrm{cB}$ \\
\hline \multirow[t]{4}{*}{ 3-hexen-1-ol acetate } & 0.0008 & 1 & Traces & Traces & Traces \\
\hline & & 3 & Traces & Traces & Traces \\
\hline & & 5 & Traces & Traces & $0.001 \mathrm{a}$ \\
\hline & & 7 & - & $0.015 \mathrm{~A}$ & $0.002 \mathrm{aB}$ \\
\hline \multirow[t]{4}{*}{ Hexyl acetate } & 0.034 & 1 & $0.826 \mathrm{aA}$ & $0.409 \mathrm{abB}$ & $1.164 \mathrm{aA}$ \\
\hline & & 3 & $0.838 \mathrm{aA}$ & $0.554 \mathrm{bA}$ & $0.894 \mathrm{aA}$ \\
\hline & & 5 & $0.958 \mathrm{aA}$ & $0.183 \mathrm{aB}$ & $0.461 \mathrm{bB}$ \\
\hline & & 7 & - & $0.099 \mathrm{aA}$ & $0.153 \mathrm{bB}$ \\
\hline Butyl 2-methyl & 0.0006 & 1 & $0.0005 a$ & Traces & Traces \\
\hline \multirow[t]{3}{*}{ butanoate } & & 3 & $0.002 \mathrm{~b}$ & Traces & Traces \\
\hline & & 5 & $0.003 b$ & Traces & Traces \\
\hline & & 7 & - & Traces & Traces \\
\hline \multirow[t]{4}{*}{ Propyl hexanoate } & 0.001 & 1 & $0.001 \mathrm{a}$ & Traces & Traces \\
\hline & & 3 & $0.001 \mathrm{a}$ & Traces & Traces \\
\hline & & 5 & $0.003 b$ & Traces & Traces \\
\hline & & 7 & - & 0.003 & Traces \\
\hline \multirow[t]{4}{*}{ Hexyl propanoate } & 0.0007 & 1 & $0.001 \mathrm{aA}$ & $0.002 \mathrm{aA}$ & $0.0007 \mathrm{aA}$ \\
\hline & & 3 & $0.001 \mathrm{aA}$ & $0.002 \mathrm{aA}$ & $0.0008 \mathrm{aA}$ \\
\hline & & 5 & $0.003 \mathrm{bA}$ & $0.002 \mathrm{aB}$ & 0.003 bA \\
\hline & & 7 & - & $0.002 \mathrm{aA}$ & $0.001 \mathrm{aA}$ \\
\hline \multirow[t]{4}{*}{ Hexyl butyrate } & Traces & 1 & $0.011 \mathrm{aA}$ & Traces & $0.003 \mathrm{aB}$ \\
\hline & & 3 & $0.017 \mathrm{bA}$ & Traces & $0.002 \mathrm{aB}$ \\
\hline & & 5 & $0.010 \mathrm{a}$ & Traces & Traces \\
\hline & & 7 & - & Traces & Traces \\
\hline \multirow[t]{3}{*}{ Ethyl octanoate } & 0.004 & 1 & $0.004 \mathrm{a}$ & Traces & Traces \\
\hline & & 3 & $0.006 b$ & Traces & Traces \\
\hline & & 5 & $0.011 \mathrm{c}$ & Traces & Traces \\
\hline
\end{tabular}


Table 1. Continuity.

\begin{tabular}{|c|c|c|c|c|c|}
\hline \multirow{2}{*}{ Aroma compound } & \multirow{2}{*}{ At harvest } & \multirow{2}{*}{ Months } & \multicolumn{3}{|c|}{ Storage condition } \\
\hline & & & RA & CA & $\mathrm{CA}+\mathrm{RA}$ \\
\hline & & 7 & - & Traces & Traces \\
\hline Hexyl 2-methyl & Traces & 1 & 0.0008 a & Traces & Traces \\
\hline \multirow[t]{3}{*}{ butanoate } & & 3 & $0.002 b$ & Traces & Traces \\
\hline & & 5 & $0.001 \mathrm{c}$ & Traces & Traces \\
\hline & & 7 & - & Traces & Traces \\
\hline \multirow[t]{4}{*}{ Hexyl hexanoate } & Traces & 1 & $0.002 \mathrm{a}$ & Traces & Traces \\
\hline & & 3 & $0.004 b$ & Traces & Traces \\
\hline & & 5 & $0.002 \mathrm{a}$ & Traces & Traces \\
\hline & & 7 & - & Traces & Traces \\
\hline
\end{tabular}

Values are mean of three repetitions. Means within the same storage period followed by different capital letters are significantly different at $\mathrm{P} \leq 0.05$ (LS means test). Means within the same storage conditions followed by different small letters are significantly different at $P \leq 0.05$ (LS means test) Traces are values below 0.0005 ppm. ND, not detected.

storage (Figure 1) $(P<0.05)$; however, by the third month of RA storage, apples had the highest ester content (70.8 ppm, mainly butyl acetate), but CA and CA + RA apples showed $88 \%$ lower ester values, with no significant differences among them (Figure 1) $(P<0.05)$.

An increase on aldehydes content was observed in all treatments, without statistical differences between CA and RA, for the three-month storage. However, aldehyde composition among CA and RA apples varied: hexanal dominated RA-treated apples, while 2-hexenal prevailed in CA apples (Table 1). A $79 \%$ increase in alcohol content was found in RA apples compared to CA apples, mainly 2-metyl-1-butanol, 1-butanol and 1-hexanol, after the same storage period. For the same period, a higher concentration of alcohols was observed on CA + RA apples when compared to CA apples, mainly due to hexanol production (Figure 1, Table 1).

At the third month of storage, RA apples showed the highest content of total VC's, mostly composed by by butyl acetate (68 ppm, $48.5 \%$ ), 2-methyl-1-butanol (33.1 ppm, $22.2 \%)$, hexanal (15.7 ppm, 11.2\%) and 2-hexenal (12.4 ppm, $8 \%)$. In contrast, CA-stored apples had a VC profile made up of 2-hexenal (19.4 ppm, $45.8 \%$ ), butyl acetate (15.8 \%, 6.7 ppm), hexanal (11.8\%, 5.0 ppm) and 1-hexanol (4.3 ppm, $10 \%)$. CA + RA apples showed a VC profile with 2-hexenal (11.4 ppm, 29.2\%), 1-hexanol (10.4 ppm, $26.4 \%$ ) and hexanal (6.4 ppm, 16.2\%). Butyl acetate ester accounted for almost $70 \%$ of total VC in RA apples, and 2-hexenal, an aldehyde, accounted for almost $35 \%$ of total VC content in CA apples.

This behavior demonstrates the delaying ripening effect in CA-stored apples, since aldehydes are precursors of alcohols, and in turn, alcohols are ester precursors. Bu- tyl acetate ester was the main compound produced under RA (66.7\%) and under CA + RA apples (34.5\%), which agrees with Drawert (1973), who found this compound to be the prevailing ester in Golden Delicious apples under RA-stored conditions. The higher ester concentration on RA apples (mainly butyl acetate) modifies sharply aroma, compared to CA apples, since butyl acetate is an impact compound in Golden Delicious apple (Kakiuchi et al., 1986), while hexanal and 2-hexenal are aldehydes related to 'unripe' flavors in Golden Delicious apples (Flath et al., 1967; Rizzolo et al., 1989).

After five months of storage, total VC content decreased sharply on RA apples, being $74 \%$ lower than after three months of storage, although still considerably higher than in CA and CA + RA apples. A significant decrease in the concentration of aldehydes on CA apples was observed (55\% lower values than on RA conditions), mainly due to a major decrease in 2-hexenal. CA + RA apples showed higher aldehyde concentration when compared to CA after five months of storage (Figure 1) $(P<0.05)$. A considerable decrease in ester concentration was found in RA apples on the fifth month of storage, an $89 \%$ lower ester content than at three months of storage. No significant difference on esters profiles was found among RA, CA, and CA + RA apples (Figure 1).

At the fifth month of storage, the main VC's on Golden Delicious apples under RA were 2-methyl-1-butanol (38 $\%, 20.2 \mathrm{ppm})$, hexanal (34\%, $18.2 \mathrm{ppm}$ ) and butyl acetate $(11 \%, 6.0 \mathrm{ppm})$, while the main VC occurring on CA apples were hexanal (31\%, $5.5 \mathrm{ppm}), 2$-hexenal (23\%, $4.0 \mathrm{ppm})$, and 2-methyl 1-propanol (14 \%, 2.5 ppm). On CA + RA apples the compounds 2-hexenal (39\%, $7.3 \mathrm{ppm})$, hexanal (24\%, $4.5 \mathrm{ppm})$, and 1-hexanol (10\%, $1.9 \mathrm{ppm})$ were the major VC produced after five months of storage. 
Finally, after seven months of storage, CA + RA apples showed a volatile's recovery, presenting $82.5 \%$ more aldehydes and $66 \%$ more alcohol concentration than CA apples (Figure 1). The main VC produced on CA+RA apples were 2-hexenal ( $43 \%, 12$ ppm), 1-hexanol (19\%, 5.3 ppm) and 2-methyl-1-propanol (10\%, 2.7 ppm), while in CA apples the major VC were hexanal (35\%, 2.5 ppm), 2-methyl1-propanol (22 \%, $1.6 \mathrm{ppm})$ and hexanol (17\%, $1.3 \mathrm{ppm})$. RA apples were not evaluated at seven months of storage, since fruit did not maintain the required quality.

\section{LOX, AAT, and ADH activity}

Lipoxygenase (LOX) may play a key role in determining the composition of volatile compounds in apple (Fellman et al., 2000). In this study an increase in LOX specific activity was observed from harvest to the first month of storage (Figure 2). No significant difference in LOX activity was found among RA and CA apples at one month of storage.
After the first month, storing fruit under CA caused a decrease in the specific activity of the enzyme (Figure 2). Lara et al. (2007) found similar results attributing this effect to $\mathrm{LOX}-\mathrm{O}_{2}$ requirements. Figure 2 shows the relationship between LOX specific activity and total aldehydes production during apple storage under RA and CA conditions. Determination coefficient $\left(r^{2}\right)$ between aldehydes and LOX activity was 0.25 for RA apples and 0.85 for CA apples. These details, along with decreased LOX specific activity observed on CA apples, could indicate that LOX activity plays an important role in controlling aldehyde production when oxygen concentration is limited.

Ester-like volatile compounds are generated by the esterification of alcohols and acyl-CoA catalyzed by the enzyme alcohol acyltransferase (AAT) (Sanz et al., 1997). The effect of storage conditions on the AAT specific activity is shown in Figure 3. The highest AAT activity was observed at harvest (208.26 $\mathrm{mU} \mathrm{mg}^{-1}$ protein). After the first month

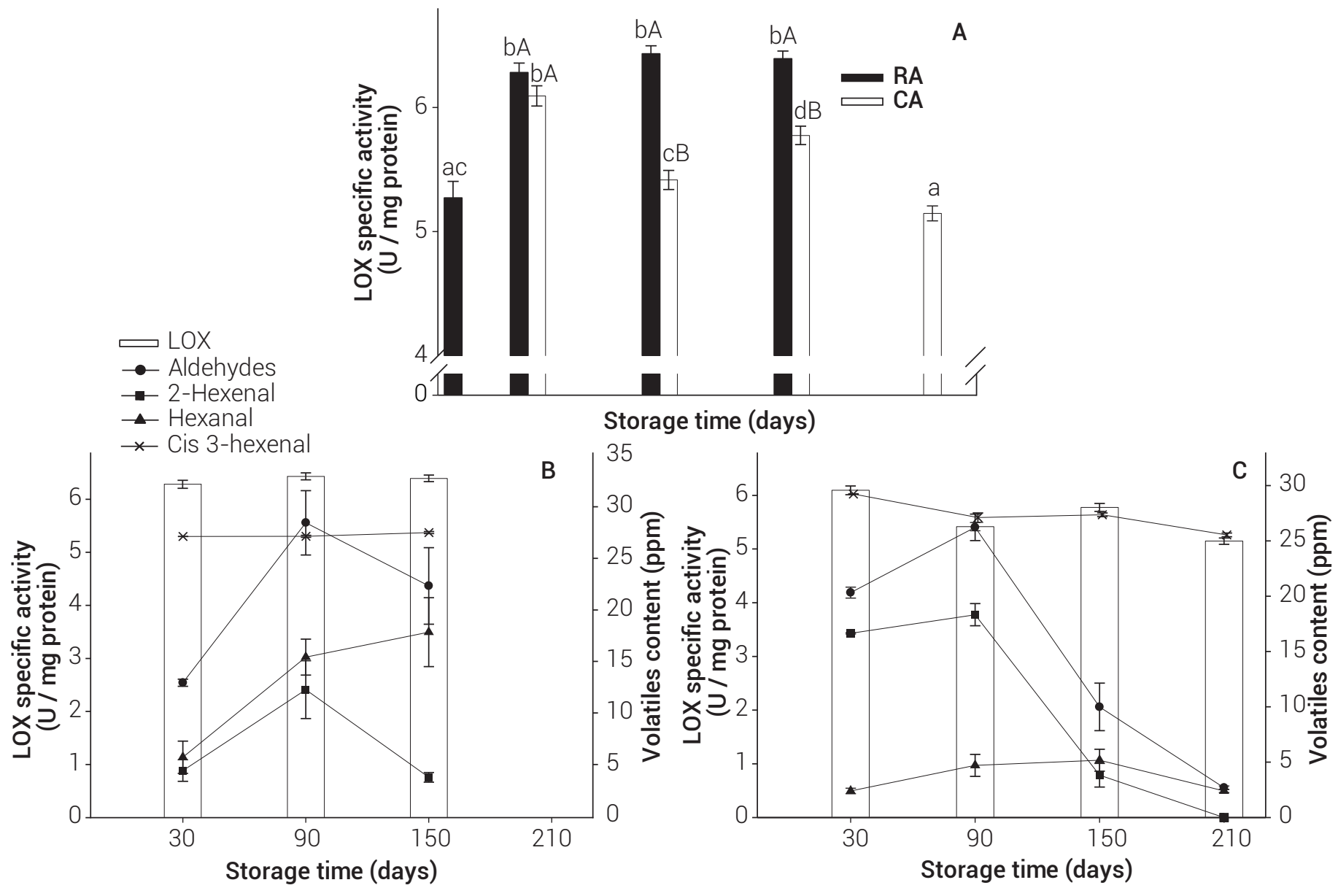

Figure 2. LOX specific activity in Golden Delicious apples at different storage conditions (A), LOX specific activity at RA (B) and at CA (C) compared to important aldehydes. Values represent mean of three repetitions. Vertical bars represent \pm SE. Means within the same storage period followed by different capital letters are significantly different at $P \leq 0.05$ (LS means test). Means within the same storage conditions followed by different small letters are significantly different at $P$ $\leq 0.05$ (LS means test). 
of storage, higher enzyme specific activity was found in RA stored fruit when compared to CA conditions $(P<0.05)$. Fellman et al. (2000) noted this same effect in Law Rome and 262 Rome apples. On RA apples, as the storage period advanced AAT specific activity decreased, suggesting enzymatic activity was affected by storage conditions.

After three months of storage there was an increase in AAT specific activity of CA apples that was not significantly different from RA apples $(P<0.05)$. Lara et al. (2007) found higher AAT specific activity in fruit stored under CA than in RA stored fruit. The highest AAT specific activity for CA apples occurred during the third month of storage, which coincides with their highest ester production. A decrease in AAT specific activity was observed in both treatments (RA and $\mathrm{CA}$ ) after five months of storage; RA showed significantly higher AAT activity than CA $(P<0.05)$.
Figure 3 shows the relationship between AAT activity and esters (total esters, butyl acetate, 2 methyl butyl acetate, and hexyl acetate) on RA and CA stored apples. RAstored apples did not show a clear connection between AAT specific activity and the ester synthesis. However, CA apples showed high correlation between AAT specific activity and total esters $\left(r^{2}=0.92\right)$. These findings could indicate that under CA conditions, ester production is correlated with AAT enzyme activity. In the case of RA apples, ester production did not show to be dependent on AAT enzyme activity. Echeverría et al. (2004a) and Villatoro et al. (2008) noted that modifications in AAT specific activity could not explain the observed behavior in the production of esters.

Figure 4 shows ADH specific activity in apples stored under $C A$ and RA $(P<0.05)$. CA apples showed higher ADH activity during storage, when compared to RA apples $(P<$ 0.05). The highest ADH activity in CA stored apples was

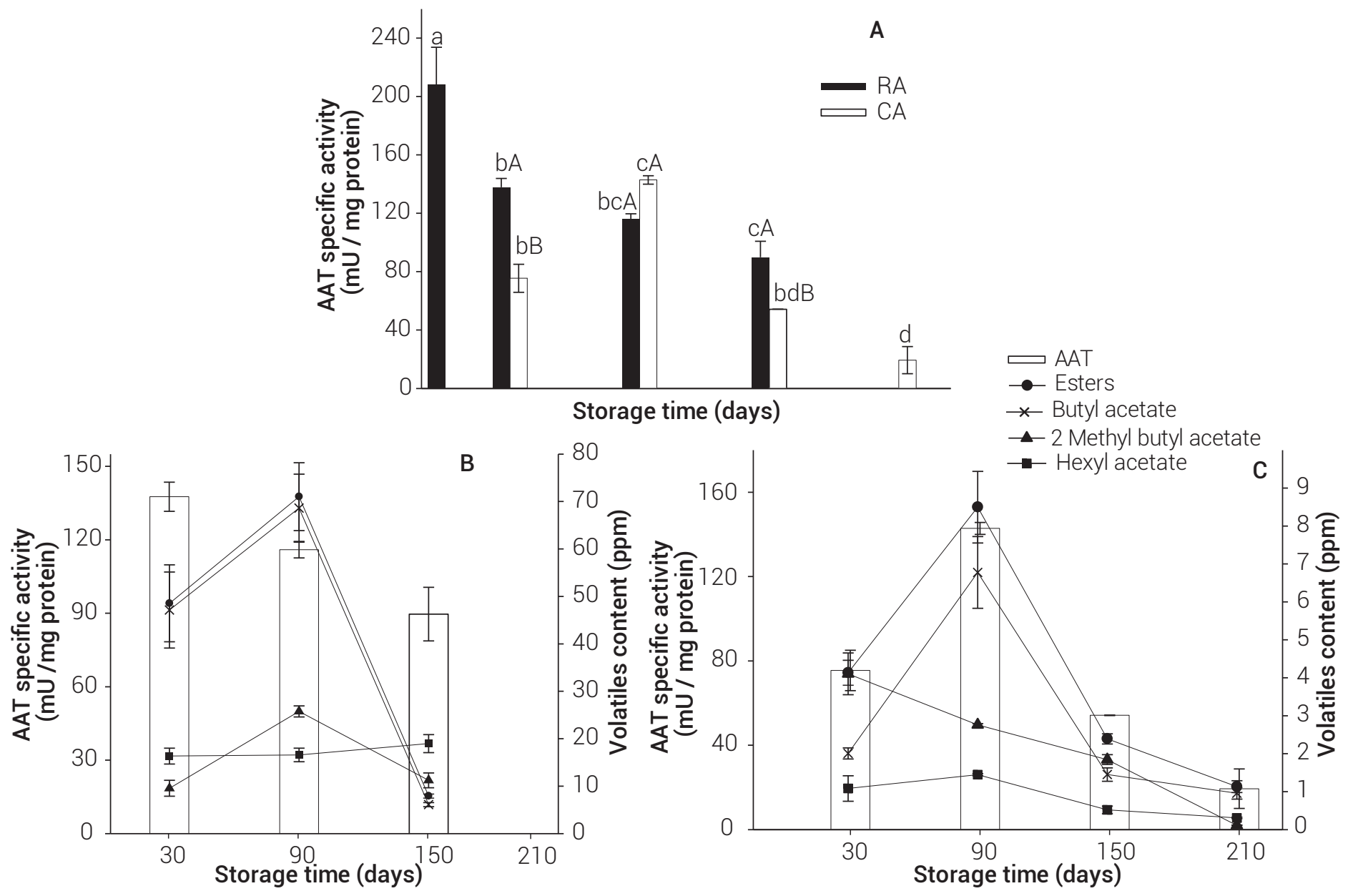

Figure 3. AAT specific activity in Golden Delicious apples at different storage conditions (A), AAT specific activity at RA (B), and at CA (C) compared to important alcohols and esters. Values represent mean of three repetitions. Vertical bars represent \pm SE. Means within the same storage period followed by different capital letters are significantly different at $P \leq 0.05$ (LS means test). Means within the same storage conditions followed by different small letters are significantly different at $P \leq 0.05$ (LS means test). 
observed after three months of storage, having values four-fold higher than RA apples. Higher ADH activity in the CA-stored apples coincided with a lower VC production; it is suggested that this enzyme activity may be related to the onset of fermentative processes after extended storage under hypoxia. Furthermore, AAT activity after extended storage under CA conditions decreased (Figure 3), thus preventing esterification of alcohol precursors (Lara et al., 2007).

\section{Fatty acids}

Fatty acids are considered the main precursors of volatile compounds; they are important structural compounds and metabolic constituents of fruit cells (Marangoni et al., 1996). They are detached and metabolized by lipase, $\beta$-oxidation enzymes and/or lipoxygenase, and they produce volatile aroma substances (Fellman et al., 2000). Figure 5 shows fatty acids obtained from RA and CA apples. Linoleic acid was found in higher concentration (85- 125 ppm), followed by palmitic acid (27 - 45 ppm), linolenic acid (5 - 17 ppm), oleic acid (3 - 12 ppm) and stearic acid (5 - $8 \mathrm{ppm})$.

Linoleic acid is considered one of the main precursors of volatile compounds in apples (Yahia, 1994). Linoleic acid concentration increased during storage in both treatments, but no significant differences were found between RA and CA $(P<0.05)$. Linoleic acid concentration, as well as the VC of the fruit stored under RA-conditions, increased continuously until the fifth month of storage, which is associated with fruit climacteric ripening (Song and Bangerth,
1996; Song and Bangerth, 2003; Defilippi et al., 2005).

Palmitic acid concentration increased on CA apples after five months of storage. Palmitic acid concentration remained steady on RA apples through storage $(P<0.05)$. Similar results were shown by Song et al. (2003) who found higher concentration of palmitic acid on CA apples after 6 months of storage. Linolenic acid concentration decreased thorough storage, more markedly in RA apples; this was the only fatty acid that decreased in concentration steadily during storage. Previous research found that linolenic acid in apples decreases with ripening, as a result of breakdown of fatty acids in chloroplasts to produce straight C-chain esters (Meigh and Hulme, 1965; Galliard, 1968). Oleic acid concentration increased after one month of storage for RA and after three months of storage in CA apples. Stearic acid content steadily increased during storage, and it reached its highest value after five months of storage. CA apples reached higher values of stearic acid after three months of storage, when compared to RA apples. Stearic acid in Jonagold apples showed similar behavior under CA conditions (Saquet et al., 2003).

No significant decrease of the fatty acid content in CAstored apples with respect to that observed in RA-stored apples was observed in this study, except for oleic acid during the first month of storage. These results differed with those found by Saquet et al. (2003), who reported that fatty acid concentrations in Jonagold apple pericarp tissue are lowered under CA storage. This suppression effect on fatty acid concentration in CA apples may be dependent upon atmospheric composition and apple variety under study,

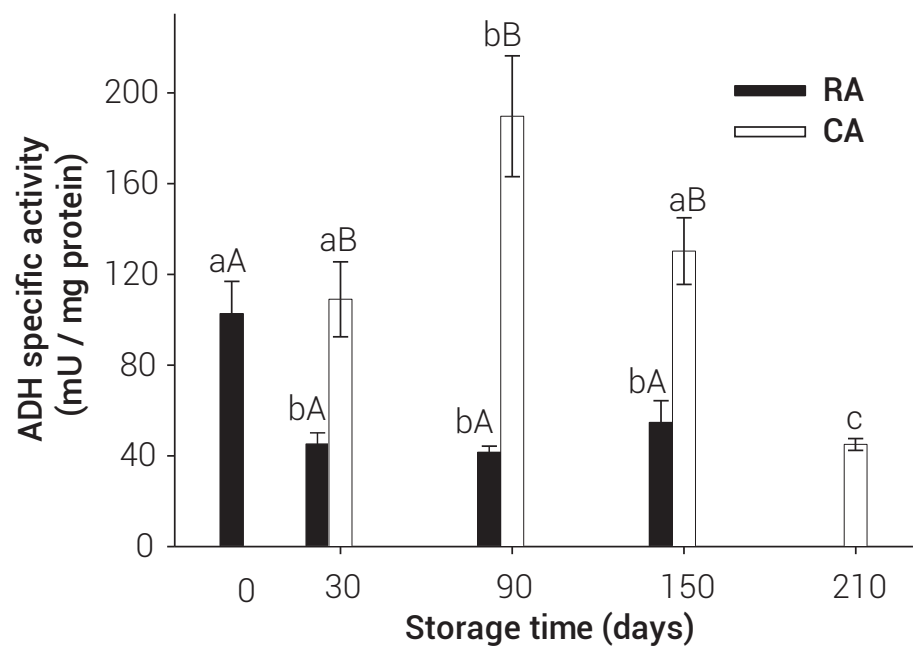

Figure 4. ADH specific activity in Golden Delicious apples at different storage conditions. Values represent mean of three repetitions. Vertical bars represent \pm SE. Means within the same storage period followed by different capital letters are significantly different at $\mathrm{P} \leq 0.05$ (LS means test). Means within the same storage conditions followed by different small letters are significantly different at $\mathrm{P} \leq 0.05$ (LS means test). 

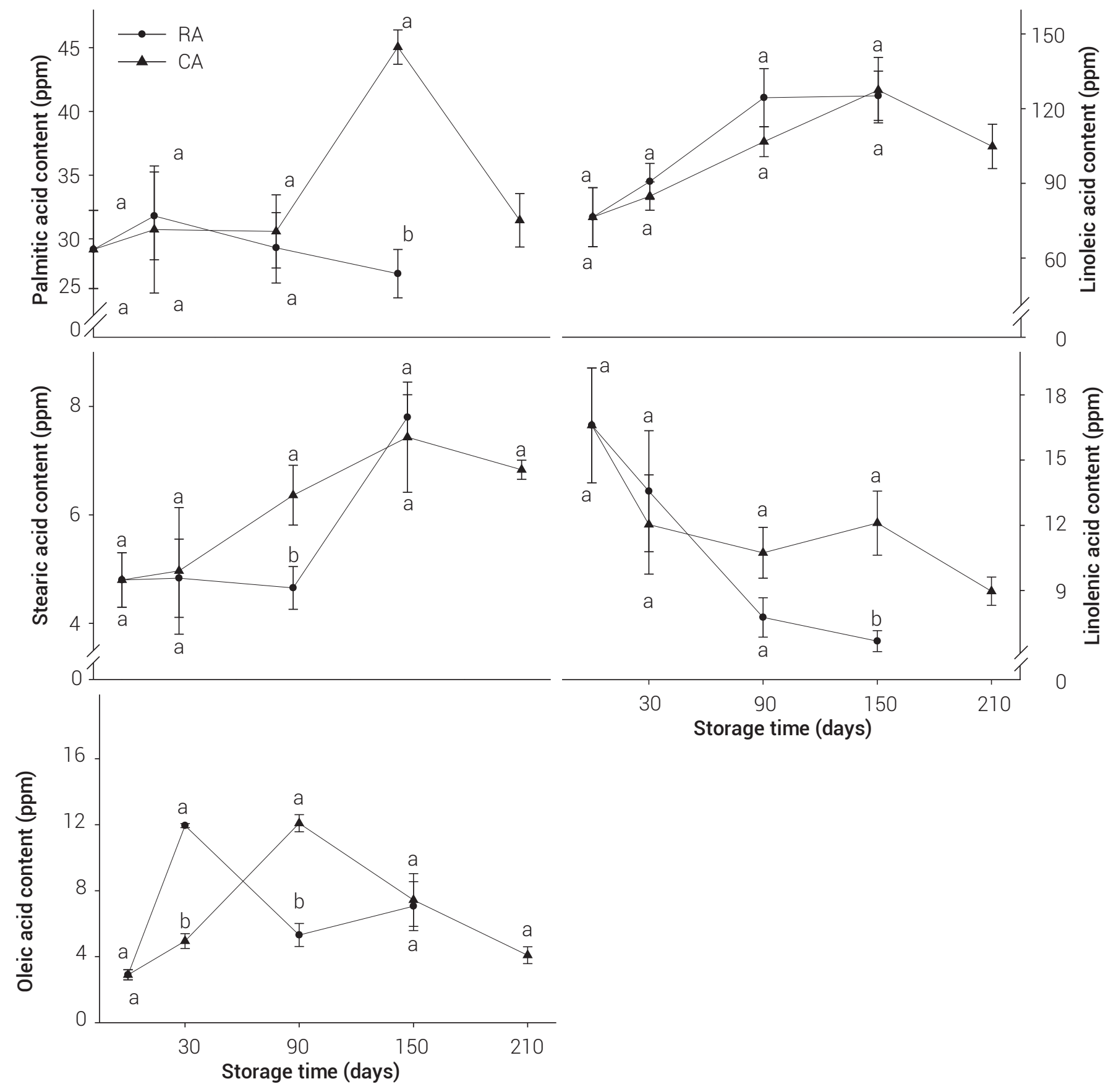

Figure 5. Fatty acids in Golden Delicious apples at different storage conditions. Values represent mean of three repetitions. Verticals bars represent $\pm S E$. Means showing different letters are significantly different at $P \leq 0.05$ (LS means test).

among other conditions.

\section{CONCLUSIONS}

Storage conditions affected composition and concentration of volatile compounds in apples. Volatile compounds synthesis decreased under CA storage. This storage conditions inhibited the production of esters butyl acetate and hexyl acetate, two key apple aroma compounds. We propose that the main cause of this reduction is the decrease in the activity of LOX and AAT enzymes at some stage during CA storage. 


\section{ACKNOWLEDGMENTS}

This research was supported by the Mexican National Council of Science and Technology (CONACyT) and Chihuahua State Government, through the $\mathrm{CHIH}$ 2010-C01-146966 FOMIX grant. Authors thank Grupo La Norteñita S.A., for providing fruit samples for this study and Unión Agricola Regional de Fruticultores del Estado de Chihuahua UNIFRUT for support.

\section{BIBLIOGRAPHY}

Altisent R., J. Graell, I. Lara, L. López and G. Echeverría (2011) Comparison of the volatile profile and sensory analysis of "Golden Reinders" apples after the application of a cold air period after ultralow oxygen (ULO) storage. Journal of Agricultural and Food Chemistry 59:6193-6201.

Berger R. G. and F. Drawert (1984) Changes in the composition of volatiles by post-harvest application of alcohols to 'Red Delicious' apples. Journal of the Science of Food and Agriculture 35:13181325

Bismark, Banco de Investigación y Marketing (2002) Manzano: Las Variedades de más Interés. $1^{\text {a }}$ ed. Irta, Barcelona, España. pp:1-63.

Brackmann A., J. Streif and F. Bangerth (1994) Influence of CA and ULO storage conditions on quality parameters and ripening of preclimateric and climateric harvested apples. Effect on colour, firmness, acidity and SS. Gartenbauwissenschaft 59:243-257.

Chang L. A., L. K. Hammett and D. M. Pharr (1982) Ethanol, alcohol dehydrogenase and pyruvate decarboxylase in storage roots of four sweet potato cultivars during simulated flood-damage and storage. Journal of the American Society for Horticultural Science 107:674-677.

Defilippi G. B., A. M. Dandekar and A. A. Kader (2005) Relationship of ethylene biosynthesis to volatile production, related enzymes, and precursor availability in apple peel and flesh tissues. Journal of Agricultural and Food Chemistry 53:3133-3141.

Defilippi G. B., D. Manríquez, K. Luengwilai and M. González-Agüero (2009) Aroma Volatiles: Biosynthesis and Mechanisms of Modulation During Fruit Ripening. Advances in Botanical Research 50:1-37.

De Pooter H. L., M. Van Acker and N. M. Schamp (1987) Aldehyde metabolism and the aroma quality of stored "Golden Delicious" apples. Phytochemistry 26:89-92.

Dhall R. K. (2013) Advances in edible coatings for fresh fruits and vegetables: a review. Critical Reviews in Food Science and Nutrition 53:435-450

Dixon J. and E. W. Hewett (2000) Factors affecting apple aroma/flavor volatile concentration: A review. New Zealand journal of Crop and Horticultural Science 28:155-173

Drawert F., R. Tressl, W. Heimann, R. Emberger and M. Speck (1973) Über die Biogenese von Aromastoffen bei Pflanzen und Früchten $\mathrm{XV}$; Enzymatisch-oxidative Bildung von c6-Aldehyden und Alkoholen und deren Vorstufen bei Apfeln und Trauben. Chemie Mikrobiologie Technologie der Lebensmittel 2:10-22.

Dürr P. and U. Schobinger (1981) The contribution of some volatiles to the sensory quality of apple and orange juice odor. In: Flavour 81. P Schreier (ed). Walter de Gruyter, Berlin. pp:179-193.

Echeverría G., J. Graell, I. Lara, M. L. López and I. Lara (2004a) Volatile production, quality and aroma-related enzyme activities during maturation of 'Fuji' apples. Postharvest Biology and Technology 31:217-227

Echeverría G., T. Fuentes, J. Graell, I. Lara and M. L. López (2004b) Relationship between volatile production, fruit quality, and sensory evaluation of 'Fuji' apples stored in different atmospheres by means of multivariate analysis. Journal of the Science of Food and Agriculture 84:5-20

Flath R., D. R. Black, D. G. Guadagni, W. H. McFadden and T. H. Schultz (1967) Identification and organoleptic evolution of compounds in 'Delicious' apple essence. Journal of Agricultural and Food Chemistry 15:29-35.
Fellman J. K., D. S. Mattinson, B. Bostick, J. P. Mattheis and M. Patterson (1993) Ester biosynthesis in Rome apples subjected to low oxygen atmospheres. Postharvest Biology and Technology 3:201-214

Fellman J. K., T. W. Miller, D. S. Mattinson and J. P. Mattheis (2000) Factors that influence biosynthesis of volatile flavor compound in apple fruits. HortScience 35:1026-1033.

Fellman J. K., D. R. Rudell, D. S. Mattison and J. P. Mattheis (2003) Relationship of harvest maturity to flavor regeneration after CA storage of "Delicious" apples. Postharvest Biology and Technology 27:39-51

Galliard T. (1968) Aspects of lipid metabolism in higher plants-II. The identification and quantitative analysis of lipids from the pulp of pre- and post-climacteric apples. Phytochemistry 7:1915-1922.

Kakiuchi N., T. Moriguchi, H. Fukuda, N. Ichimura, Y. Kato and Y. Banba (1986) Composition of volatile compounds of apple fruits in relation to cultivars. Journal of the Japanese Society for Horticultural Science 55:280-289

Kader A. A. (2002) Modified atmospheres during transport and storage. In: Postharvest Technology of Horticultural Crops. A. A. Kader (ed). Univesity California., Oakland, Calif. pp:135-144.

Lara I., G. Echeverría, J. Graell and M. L. López (2007) Volatile emission after controlled atmosphere storage of Mondial Gala apples ( $\mathrm{Ma}$ lus domestica): Relationship to some involved enzyme activities. Journal of Agricultural and Food Chemistry 55:6087-6095

López M. L., T. Lavilla, M. Riba and M. Vendrell (1998) Comparison of volatile compounds in two seasons in apples: 'Golden Delicious' and 'Granny Smith'. Journal of Food Quality 21:155-166.

López M. L., T. Lavilla, I. Recasens, J. Graell and M. Vendrell (2000) Changes in aroma quality of 'Golden Delicious' apples after storage at different oxygen and carbon dioxide concentrations. Journal of the Science of Food and Agriculture 80:311-324.

Lumpkin C., J. K. Fellman, D. R. Rudell and J. P. Mattheis (2015) 'Fuji' apple (Malus domestica Borkh) volatile production during high $\mathrm{pCO}_{2}$ controlled atmosphere storage. Postharvest Biology and Technology 100:234-243

Marangoni A. G., T. Palma and D. W. Stanley (1996) Membrane effects in postharvest physiology. Postharvest Biology and Technology 7:193-199.

Mattheis J. P., D. A. Buchanan and J. K. Fellman (1995) Volatile compound production by "Bisbee Delicious" apples after sequential atmospheres storage. Journal of Agricultural and Food Chemistry 43:1902-1906.

Maya-Meraz I. 0., Espino-Díaz M., Molina-Corral F. J., González-Aguilar G. A., Jacobo-Cuellar J. L., Sepulveda D. R. and Olivas G. I. (2014) Production of volatiles in fresh-cut Apple: Effect of applying alginate coatings containing linoleic acid or isoleucine. Journal of Food Science 79:C2185-C2191

Meigh D. F. and A. C. Hulme (1965) Fatty Acid Metabolism in the apple fruit during the respiration climacteric. Phytochemistry 4:863871

NIST (1998) National Institute of Standards and Technology, Mass Spectral Library. Database and Software. Version 1.7, USA.

Pérez A. G. and C. Sanz (2008) Formation of fruit flavor: In: Fruit and Vegetable Flavour. B. Bruckner and W. S. Grant (eds.). Cambridge. England. pp:41-70.

Pérez A. G., C. Sanz, R. Olías, J. J. Ríos and J. M. Olías (1996) Evolution of strawberry alcohol acyltransferase activity during fruit development and storage. Journal of Agricultural and Food Chemistry 44:3286-3290

Petró-Turza M., I. Szarföldi-Szalma, E. Madarassy-Mersich, G. Teleky-Vamossy and K. Füzesi-Kardos (1986) Correlation between chemical composition and sensory quality of natural apple aroma condensates. Die Nahrung Food 30:765-774

Rizzolo A., A. Polesello and G. Y. Teleky-Vamossy (1989) CGC/Sensory analysis of volatile compounds developed from ripening apple fruit. Journal of High Resolution Chromatography 12:824-827.

Sanz C. J., M. Olias and A. G. Pérez (1997) Aroma biochemistry of fruits and vegetables. In: Phytochemistry of Fruit and Vegetables. F. A. Tomas-Barberan and R. J. Robins (eds.). New York, Oxford University. pp:125-155.

Saquet A. A., J. Streif and F. Bangerth (2003) Impaired aroma production of CA-stored "Jonagold" apples as affected by adenine and pyridine 
nucletotide levels and fatty acid concentrations. Journal of Horticultural Science and Biotechnology 78:695-705.

SIAP, Servicio de Información Agroalimentaria y Pesquera (2010) Secretaría de Agricultura, Ganadería y Recursos Pesqueros, México. www. siap.sagarpa.gob.mx.

SAS (2009) Statistical Software, version 9 (SAS Institute, Cary, NC, USA)

Singh H. P., D. P. Murr, G. Paliyath and J. R. DeEll (2010) Aroma volatile biosynthesis in 'Gala' apples stored in controlled atmosphere. ISHS Acta Horticulturae 857:115-122.

Song J. and F. Bangerth (1996) The effect of harvest date on aroma compound production from 'Golden Delicious' apple fruit and relationship to respiration and ethylene production. Postharvest Biology and Technology 8:259-269.

Song J. and F. Bangerth (2003) Fatty acids as precursors for aroma volatile biosynthesis in pre-climacteric and climacteric apple fruit. Postharvest Biology and Technology 30:113-121.
Starr C., S. Mattinson and J. Fellman (2010) Analysis of the control of the most important flavor production process occurring in apples. WSU Academic Showcase Posters (64). http://hdl.handle net/2376/2574.

Villatoro C., R. Altisent, G. Echeverría, J. Graell, M. L. López and I. Lara (2008) Changes in biosynthesis of aroma volatile compounds during on tree maturation of "Pink Lady" apples. Postharvest Biology and Technology 47:286-295.

Wang Y. S., S. P. Tian, Y. Xu, G. Z. Qin and H. J. Yao (2004) Changes in the activities of pro-and anti-oxidant enzymes in peach fruit inoculated with Cryptococcus laurentii or Phenicillium expansum at 0 or $20^{\circ} \mathrm{C}$. Postharvest Biology and Technology 34:21-28.

Yahia E. M. (1994) Apple flavor. Horticultural Reviews 16:197-234

Young J. C., G. Chu, X. Liu and H. Zhu (2004) Ester variability in apple varieties as determined by solid-phase microextraction and gas chromatography-mass spectrometry. Journal of Agricultural and Food Chemistry 52:8086-8093. 